\title{
Gestão de resíduos: um estudo de caso no setor de logística reversa da companhia energética de Minas Gerais
}

\author{
Marco Aurélio Ramos', Sergio Geraldo Maia², Alfredo Alves de Oliveira Melo³ \\ 'Coordenador do curso de Administração na Faculdade Novos Horizontes - Belo Horizonte, MG - Brasil \\ ${ }^{2}$ Graduado em Administração pela Faculdade novos Horizontes - Belo Horizonte, MG - Brasil \\ ${ }^{3}$ Professor e Pesquisador do Programa de Mestrado Acadêmico da Faculdade Novos Horizontes - Belo Horizonte, MG - Brasil
}

\section{Resumo}

A partir de um estudo de caso, realizado no Setor de Logística Reversa da Companhia Energética de Minas Gerais (Cemig), o presente artigo traz uma abordagem a respeito do tema gestão de resíduos. A pesquisa desenvolvida tem o objetivo de investigar a importância da gestão de resíduos para a organização, a partir de uma visão interna, identificada por meio de análise documental e entrevistas com gestores envolvidos no processo estudado. As informações levantadas na pesquisa de campo foram analisadas de maneira qualitativa. Os estudos feitos indicaram, de maneira geral, a existência na organização de um processo bem estruturado de gerenciamento de resíduos, reconhecido internamente como agregador de valor ao negócio da empresa, principalmente em termos dos requisitos da sustentabilidade. Entretanto, também foram identificados alguns desafios inerentes à gestão de resíduos, como em aspectos ligados ao atendimento à legislação e pelas exigências de diferentes formas de atuação, diante da grande diversidade de materiais a serem destinados. Ressalta-se, ainda, que as atividades inseridas no contexto do setor investigado, dentre elas a gestão de resíduos, não contemplam o retorno de mercadorias aos fabricantes/fornecedores, evidenciando um processo a princípio eficiente, porém, parcialmente distanciado do real conceito de logística reversa.

Palavras-chave: Logística Reversa; Gestão de Resíduos; Sustentabilidade.

\begin{abstract}
From a case study, performed at the Reverse Logistics Companhia Energetica de Minas Gerais (Cemig), this paper presents an approach on the subject of waste management. The research has developed to investigate the importance of waste management for the organization, from an inner vision, identified by means of document analysis and interviews with managers involved in the process studied. The information gathered in field research were analyzed in a qualitative manner. The studies showed, in general, the existence in the organization of a well structured management of waste, known internally as aggregating value to the business, especially in terms of the requirements of sustainability. However, we also identified some challenges in waste management, such as aspects related to compliance with the law and the requirements of different forms of action, given the great diversity of materials to be designed. It should be noted also that the activities within the context of the sector investigated, among them the management of waste does not include the return of goods to manufacturers / suppliers, showing an efficient process in principle, however, partially detached from the real concept of logistics reverse.
\end{abstract}

Key-words: Reverse Logistics; Waste Management; Sustainability. 


\section{INTRODUÇÃO}

Este artigo aborda os aspectos relacionados à Gestão de Resíduos, tendo como objeto de estudo o Setor de Logística Reversa da Companhia Energética de Minas Gerais (Cemig). Dentre as diversas atividades que integram o macroprocesso gerido pelo setor investigado, o estudo centra-se na análise de um ponto crítico de gestão, onde, por exemplo, em termos de destinação de resíduos, ainda não se observa um consenso no mercado sobre as melhores práticas.

Inúmeros fatores têm levado a logística reversa a ocupar, cada vez mais, lugar de destaque dentro do conjunto de operações realizadas pelas organizações. Estes fatores incluem desde questões ligadas à própria eficiência operacional, o que engloba aspectos relacionados à otimização dos custos, como o reaproveitamento e a reciclagem de materiais, até questões de ordem legal, no que diz respeito, por exemplo, às exigências de natureza socioambiental. Desta forma, a sustentabilidade empresarial, hoje tida como condição fundamental para sobrevivência das organizações, se torna impensável sem a prática de uma gestão sobre o fluxo reverso de mercadorias, usadas ou não, oriundas de processos internos ou de devoluções dos clientes.

Dentre as atividades envolvidas no processo de logística reversa, tem-se uma atenção especial para a destinação dada aos resíduos, seja pelo simples zelo à imagem organizacional perante seus stakeholders, ou devido aos riscos de penalidades, como multas e sanções, impostas pelos órgãos fiscalizadores. No Brasil, as diferentes instâncias governamentais (municipal, estadual e federal) atuam por intermédio de diversos órgãos, como fundações, institutos, conselhos e secretarias, impondo uma série de regulamentações que, inevitavelmente, despertam o interesse para o tema.

O estudo da logística de forma integrada é relativamente recente, em comparação com outras áreas mais tradicionais, como por exemplo, marketing e finanças. Apenas na década de 60 que se têm as primeiras publicações a respeito da importância da logística empresarial. Dentre as definições de logística, Ballou (2006, p. 27) defende que a mais completa seria aquela promulgada pelo Coucil of Logistics Management (CLM), organização de gestores, educadores e profissionais da área, fundada em 1962, nos Estados Unidos. A definição do CLM é a seguinte:

Logística é o processo de planejamento, implantação e controle do fluxo eficiente e eficaz de mercadorias, serviços e das informações relativas desde o ponto de origem até o ponto de consumo com o propósito de atender às exigências dos clientes.

Conforme Pozo (2004), as atividades de logística são divididas em duas categorias, primárias e de apoio. As atividades primárias são aquelas primordiais para o atendimento dos objetivos logísticos, seja de custo ou de nível de serviço exigido pelo mercado. São as três atividades que representam a maior parcela do custo total da logística: transportes, manutenção de estoques e processamento de pedidos. As atividades de apoio são aquelas que dão suporte às atividades primárias, são elas: armazenagem, manuseio de materiais, embalagem, suprimentos, planejamento e sistema de informação.

Segundo Ballou (2006), outro conceito importante é o de Gerenciamento da Cadeia de Suprimentos (GCS ou SCM, do inglês Supply Chain Management) termo mais recente que ultrapassa a definição de logística integrada, pondo em destaque as interações entre as funções de marketing, logística e produção. O GCS considera tanto o âmbito da empresa, quanto as interações com os demais envolvidos no canal de fluxo dos produtos.

Dentre os diversos processos presentes na logística das organizações, a crescente demanda pelos componentes da sustentabilidade empresarial coloca em destaque a chamada logística reversa, que, segundo Arbache et al (2007), compreende o fluxo inverso de produtos, ou seja, dos clientes para a empresa. Para os autores, este é um processo cada vez mais importante para as empresas, em função, por exemplo, dos movimentos em prol da reutilização de materiais e da reciclagem.

De forma semelhante, Adlmaier e Sellitto (2007) descrevem a logística reversa como o movimento de bens na direção oposta à original, ou seja, representa um fluxo que parte do consumidor em direção ao produtor. A logística reversa vem sendo reconhecida como a área da logística empresarial que planeja, opera e controla o fluxo e as informações logísticas correspondentes ao retorno de bens ao seu ciclo produtivo de origem ou à sua destinação, como matéria-prima, a outro ciclo produtivo. $\mathrm{O}$ bem pode retornar no estado próximo ou igual ao original (devido a problemas de qualidade, defeitos de fabricação, erros de projeto, erros de expedição, consignações não requisitadas, sobras, obsolescência tecnológica, etc.) ou em forma de resíduos, rejeitos ou refugos, neste caso, pela incapacidade de quem utiliza os materiais de dar destinação adequada às partes 
resultantes do consumo.

Também de opinião análoga aos demais autores, Lacerda (2009) define o processo de logística reversa como um gerador de materiais reaproveitáveis. Este processo engloba diversas atividades empresariais, voltadas para a coleta, separação, embalagem e expedição de itens usados, danificados ou obsoletos, partindo dos pontos de consumo com destino aos locais de revenda, reprocessamento ou de descarte.

Ainda segundo Lacerda (2009), os materiais podem passar por diferentes tipos de reprocessamento, dependendo das condições em que estes entram no sistema de logística reversa. Os materiais podem, por exemplo, retornar ao fornecedor, serem recondicionados, reciclados ou, em último caso, o destino pode ser o seu descarte final.

Segundo Gonçalves e Marins (2006), o conceito de logística reversa deve ser estruturado a partir de três aspectos relevantes, com respeito aos produtos e suas respectivas embalagens. Os três pontos indicados pelos autores são a própria questão logística, a questão financeira e a ambiental. Do ponto de vista logístico, o ciclo de vida de um produto não se encerra com a sua entrega ao cliente/ consumidor. Produtos que se tornam obsoletos, danificados ou não funcionam devem retornar ao seu ponto de origem para serem adequadamente descartados, reparados ou reaproveitados. Em termos financeiros, existe o custo relacionado ao gerenciamento do fluxo reverso, que se soma aos custos de compra de matéria-prima, de armazenagem, transporte e estocagem, já tradicionalmente considerados na logística. Por último, do ponto de vista ambiental, devem ser considerados e avaliados, os impactos do produto sobre o meio ambiente durante toda sua vida. Este tipo de visão sistêmica é importante para que o planejamento logístico envolva todas as etapas do ciclo do produto.

Desta forma, faz-se necessário analisar a situação do ponto de vista holístico, com uma combinação dos três pontos de vista acima descritos, para permitir o planejamento da rede logística, de forma a englobar todas as fases do ciclo de vida dos produtos, os custos associados e os impactos ambientais decorrentes (GONÇALVES E MARINS, 2006).

Um conceito mais específico de logística reversa está definido no Inciso XII, Art. 3. da Lei n ${ }^{\circ}$ 12.305 de 02/08/2010 (Lei dos Resíduos Sólidos):

Logística reversa: instrumento de desenvolvimento econômico e social caracterizado por um conjunto de ações, procedimentos e meios destinados a viabilizar a coleta e a restituição dos resíduos sólidos ao setor empresarial, para reaproveitamento, em seu ciclo ou em outros ciclos produtivos, ou outra destinação final ambientalmente adequada.

De acordo com Araújo e Juras (2011), observa-se nesta definição uma associação da logística reversa com o desenvolvimento econômico e social. Além disso, a logística reversa é tida como um instrumento diretamente relacionado com os mecanismos de gestão de resíduos adotados pelas empresas, contemplando desde a coleta, até a disposição final de forma ambientalmente correta.

Souza e Fonseca (2009) afirmam que a logística reversa tem como papel principal atender aos princípios de sustentabilidade ambiental. Para alcançar este objetivo as empresas devem adotar processos de produção limpa e assumirem a responsabilidade pelo destino final dos produtos gerados, de forma a reduzir o impacto ambiental que eles causam. Os canais reversos organizados pelas empresas visam dar uma melhor destinação aos materiais, como a reutilização ou a reciclagem.

Segundo Pereira et al (2012), a sustentabilidade empresarial representa um grande desafio para as organizações, principalmente pela necessidade de uma visão de longo prazo. O objetivo fundamental das empresas continua sendo a geração de retornos financeiros, tornando os investimentos em projetos de sustentabilidade muitas vezes inviáveis por não apresentarem um retorno imediato.

De opinião semelhante, Dias (2011) afirma que, mesmo sendo visível uma maior mobilização empresarial na busca da sustentabilidade, o foco ainda é voltado para o ambiente interno. A sustentabilidade, neste caso, compreende apenas uma forma de gestão mais eficiente, com melhor aproveitamento dos recursos, o que não significa desenvolvimento econômico sustentável. Entretanto, o autor reconhece que, lentamente, o papel das organizações, antes focadas na produção, está mudando no sentido de assumirem uma maior responsabilidade social, onde se inclui a perspectiva ambiental.

Outros autores, como Ribeiro e Morelli (2009), acreditam que a preocupação com a sustentabilidade já faz parte do contexto organizacional global. Para justificar este ponto de vista os autores citam a criação, em 1999, dos Índices Mundiais de Sustentabilidade da Dow Jones (Dow Jones Sustainability World Indexes - DJSI World), com o objetivo de monitorar o desempenho das empresas líderes em sustentabilidade, evidenciando uma maior valorização das questões ambientais. 
Almeida (2002) explica que o Índice Dow Jones de Sustentabilidade identifica organizações capazes de gerar ganhos de longo prazo, por considerarem em suas análises de riscos e oportunidades, os aspectos econômicos, sociais e ambientais.

Ainda segundo Almeida (2002), as ações voltadas para a sustentabilidade são, acima de tudo, de caráter preventivo. Isto inclui uma preocupação organizacional com os custos futuros de suas operações e não apenas com a lucratividade no presente. A empresa que quer ser sustentável busca uma melhoria contínua de sua reputação, seja através dos ganhos em eficiência ou por meio de investimentos em inovações tecnológicas e de gestão. Desta forma, o autor defende que a sustentabilidade resulta de uma combinação entre ecoeficiência e responsabilidade social. Ecoeficiência significa produzir melhor e em maior quantidade e, ainda, zelando pela redução da poluição e do uso de recursos naturais. Já a responsabilidade social está relacionada com as ações integradoras desenvolvidas pelas empresas no ambiente social no qual influi e, ao mesmo tempo, do qual recebe influência.

Segundo Ribeiro e Morelli (2009), a geração de resíduos é inerente aos diversos ramos industriais, como o metalúrgico, o químico e o petroquímico, o de papelaria, o alimentício, etc.. Os autores ainda destacam a grande diversidade de lixo industrial gerado, citando como exemplos as cinzas, lodos, óleos, resíduos alcalinos ou ácidos plásticos, papel, madeira, metal, borracha, vidros, entre outros.

Um importante conceito apresentado na Lei 12.305/2010 é a da definição de Resíduos Sólidos. A partir dessa definição é possível compreender o universo de materiais a serem considerados pela gestão de resíduos. De acordo com o Art. 3. da Lei $\mathrm{n}^{\mathrm{o}} 12.305$ de $02 / 08 / 2010$, no Inciso XVI, tem-se:

Resíduos sólidos: material, substância, objeto ou bem descartado resultante de atividades humanas em sociedade, a cuja destinação final se procede, se propõe proceder ou se está obrigado a proceder, nos estados sólido ou semissólido, bem como gases contidos em recipientes e líquidos cujas particularidades tornem inviável o seu lançamento na rede pública de esgotos ou em corpos d'água, ou exijam para isso soluções técnica ou economicamente inviáveis em face da melhor tecnologia disponível.

As definições dadas pela Lei dos Resíduos
Sólidos consideram a gestão de resíduos como um conjunto de ações exercidas, direta ou indiretamente, nas etapas do processo logístico reverso, incluindo a coleta, transporte, trasbordo, tratamento e destinação final ambientalmente correta dos resíduos sólidos e disposição final ambientalmente adequada dos rejeitos. Vale ressaltar que as medidas adotadas no gerenciamento de resíduos devem estar alinhadas com os planos municipais de gestão integrada de resíduos sólidos ou com o plano de gerenciamento de resíduos sólidos, exigidos na forma da Lei. (ARAÚJO; JURAS, 2011).

Ao comentar a definição dada pela Associação Brasileira de Normas Técnicas (ABNT), por meio da NBR 10.004/2004 (Resíduos Sólidos - Classificação), que fundamenta a classificação considerada pela Lei 12.305/2010, Ribeiro e Morelli (2009) chamam a atenção para a abrangência do conceito, que considera como resíduos sólidos também aqueles nos estados semissólido, líquido ou gasoso.

Ainda segundo os autores, existem diversas formas de classificação de resíduos, destacando-se aquela dada pela norma NBR 10.004/2004. A ABNT, através desta norma, usa como critério de classificação dos resíduos sólidos os seus riscos potenciais ao meio ambiente e à saúde pública. Desta forma, os resíduos são tidos como Classe I (Perigosos) - quando apresentam riscos em função de características de inflamabilidade, corrosividade, reatividade, toxicidade ou patogenicidade - ou Classe II (Não Perigosos) - quando não apresentam os riscos inerentes aos de Classe I. Esta classificação subdivide os resíduos Classe II em Não Inertes (Classe II A) - quando apresentam características de combustibilidade, biodegradabilidade ou solubilidade - e Inertes (Classe II B) - aqueles que não apresentam constituintes solúveis em água em concentrações superiores aos padrões de potabilidade.

Dentre os diversos problemas associados à existência dos resíduos, Ribeiro e Morelli (2009, pag. 49) chamam a atenção para as ocorrências de acidentes ambientais. Conforme os autores, "o resíduo industrial é um dos maiores responsáveis pelas agressões fatais ao ambiente", em função da presença de metais, solventes e outros produtos químicos.

De acordo com Pereira et al (2012), a má gestão dos resíduos implica em problemas de ordem financeira, social e ambiental. De maneira geral, resíduos são matérias-primas não aproveitadas e o seu descarte sem critérios pode significar perdas financeiras. Resíduos também podem causar danos à saúde humana, o que os tornam um problema 
social. Por último, tem-se a questão ambiental, evidenciada pelas possibilidades de poluição e contaminação do meio ambiente, resultantes de uma disposição final inadequada.

Segundo Barbieri (2004), ao gerir questões que envolvam o meio ambiente, deve-se atentar para a solução dos problemas sem perder de vista as implicações mais globais relacionadas às ações praticadas. Para tornar uma gestão ambiental eficaz é necessária uma integração dos diversos agentes da sociedade em torno de objetivos comuns, definindo ações que atendam aos interesses econômicos, por parte da empresa, e sociais, por parte da comunidade.

O volume crescente e os impactos causados pela disposição inadequada no meio ambiente têm motivado a promulgação de leis que visam regulamentar as condições de geração e destinação de resíduos. Leite (2003) argumenta que as primeiras leis à respeito da destinação de resíduos, promulgadas a partir da década de 70 , impunham aos governos locais a obrigação de solucionar a questão. Entretanto, as legislações modernas tendem a responsabilizar os fabricantes pelos impactos de seus produtos ao meio ambiente. Estas leis trazem obrigações diretas, como a exigência de recolher produtos pós-consumo, ou indiretas, quando proíbem a disposição de resíduos em aterros sanitários.

Pereira et al (2012) também consideram que, com o desenvolvimento da sociedade e dos meios de produção, o poder público, antes responsável pela coleta e destinação dos resíduos, vem transferindo a responsabilidade para as empresas geradoras. Segundo estes autores, as legislações relacionadas à destinação de resíduos possuem, além dos componentes reguladores, orientadores e disciplinares, características punitivas que atingem de forma pesada aqueles que descumprem as leis.

Conforme Araújo e Juras (2011), dentre as principais leis brasileiras de proteção ao meio ambiente, destacam-se a Lei da Política Nacional do Meio Ambiente (Lei 6.938/1981), Lei de Crimes Ambientais (Lei 9.605/1998), Código Florestal (Lei 4.771/1965) e a Lei de Recursos Hídricos (Lei 9.433/1997). Ao tratar especificamente da destinação de resíduos, a Lei n ${ }^{\circ} 12.305$, de 02 de agosto de 2010, que institui a Política Nacional de Resíduos Sólidos, estabelece as diretrizes mínimas para solucionar um dos mais graves problemas ambientais do país.

A importância da Lei 12.305/2010 está na sua abrangência, pois, vai além da regulamentação sobre disposição ou aproveitamento dos resíduos gerados, definindo medidas para mudar os padrões de produção e consumo, o que exige envolvimento de toda a sociedade. Instrumentos como a responsabilidade compartilhada pelo ciclo de vida do produto e a logística reversa dão sustentação às proposições da referida Lei (ARAÚJO; JURAS, 2011).

Uma boa gestão dos resíduos gerados nos processos industriais pode configurar em oportunidades de geração de receitas. Segundo Ribeiro e Morelli (2009) a movimentação comercial relacionada aos resíduos no Brasil tem potencial para chegar a R\$ 1 bilhão por ano. Com o objetivo de estimular esse mercado, a Federação das Indústrias de Estado de São Paulo (FIESP) criou a Bolsa de Resíduos Industriais, onde são negociados mais de 200 tipos de materiais, de plásticos a silicones industriais. As negociações realizadas via "bolsa de resíduos" demonstram que aquilo que se torna um problema para uma empresa pode se configurar em uma oportunidade para outra.

Pereira et al (2012) explicam que as indústrias cimenteiras são uma alternativa bastante utilizada para o aproveitamento de resíduos sólidos. Além do consumo em grandes quantidades, o processo de produção de cimento comporta diversos tipos de resíduos, com diferentes propriedades físicas ou químicas.

Paralelo aos ganhos financeiros resultantes de uma boa gestão ambiental está a valorização da imagem empresarial perante os diversos públicos relacionados à sua atividade. Diante da globalização dos mercados, a responsabilidade ambiental se torna fator de competitividade empresarial, seja pela conscientização dos consumidores, ou pelo aumento do controle governamental, em função de acordos internacionais (DIAS, 2011).

Para Ribeiro e Morelli (2009) a elaboração da ISO $14000^{1}$ serviu como incentivo para que as empresas passassem a investir no gerenciamento de seus resíduos, buscando maior eficiência. Segundo os autores, a melhoria da imagem organizacional, resultante de uma certificação, se traduz em resultado financeiro com o aumento das vendas.

Outro ponto a ser destacado é a tendência

\footnotetext{
${ }^{1}$ ISO 14000 é um conjunto de normas que estabelecem diretrizes sobre a área de gestão ambiental dentro de empresas (privadas e públicas). Estas normas foram definidas pela International Organization for Standardization - ISO (Organização Internacional para Padronização). Para conseguir e manter o certificado ISO 14000 , as empresas precisam seguir a legislação ambiental do país, treinar e qualificar os funcionários para seguirem as normas, diagnosticar os impactos ambientais que está causando e aplicar procedimentos para diminuir os danos ao meio ambiente.
} 
no mundo corporativo da busca pelas certificações de qualidade e ambiental (geralmente no padrão ISO 9001 e 14001, respectivamente) que, de certa forma, obriga as empresas a reverem seus valores e processos, passando a considerarem impactos, e também alternativas, antes ignorados. No caso da organização estudada - empresa de grande porte, de capital aberto e com ações negociadas, inclusive, em bolsas internacionais - a questão se potencializa, em função da maior proporção dos danos causados por uma eventual falha no processo de gestão.

Diante dos motivos apresentados, o objetivo deste artigo é investigar a relevância da gestão de resíduos para a organização, tanto pela ótica da eficiência organizacional e do atendimento à legislação, como pela exigência (direta ou indireta) do próprio mercado, onde, compulsoriamente, diminuem-se os espaços para desperdícios e desrespeitos às questões legais e socioambientais.

\section{METODOLOGIA}

Considerando o objetivo deste artigo, realizou-se uma pesquisa qualitativa de caráter descritiva. Michel (2005) explica que na pesquisa qualitativa os resultados dependem também do pesquisador, de sua compreensão e interpretação dos dados. Uma pesquisa qualitativa propõe que os dados devem ser analisados mediante um contexto, observando a lógica, a coerência e a ligação entre as informações. A pesquisa descritiva, de acordo com Cervo e Bervian (2002), permite levantar as características dos fenômenos estudados e identificar as correlações entre os fatos.

A pesquisa de campo usada como base para elaboração deste artigo é composta por um Estudo de Caso que, segundo Michel (2005), permite um levantamento qualitativo aprofundado sobre a unidade que se investiga. Para isso o pesquisador pode se valer de diversas técnicas de coleta de dados, reunindo um maior número de informações, de forma a compreender todas as variáveis da unidade analisada.

O objeto de estudo deste artigo foi o Setor de Logística Reversa da Cemig, que, além de ser o núcleo das atividades relacionadas à Gestão de Resíduos na empresa, é responsável pela gestão dos materiais retornados, provenientes de sobras de obras e material salvado de instalações que sofreram modificações em projetos, como Linhas de Distribuição e Transmissão, Subestações e Usinas Hidrelétricas. Também é atribuição da área a gestão e a destinação de sucatas advindas das atividades de manutenção, além dos ativos desativados e materiais de estoque considerados inservíveis ou obsoletos.

Usou-se como principal mecanismo de coleta de dados entrevistas semiestruturadas com quatro gestores da empresa, envolvidos diretamente no processo de gestão de resíduos. Segue uma descrição resumida das atribuições de cada entrevistado: Entrevistado 01: Engenheiro de Logística com a função de coordenar a área de Logística Reversa; Entrevistado 02: Engenheira Ambiental, envolvida nos processos de destinação de resíduos perigosos; Entrevistado 03: Analista de Logística responsável pela gestão dos contratos de coprocessamento ${ }^{2}$ e incineração ${ }^{3}$ de resíduos; Entrevistado 04: Supervisor do Setor de Alienação, onde são comercializados os resíduos com valor comercial. Ressalta-se que foram elaborados roteiros específicos para cada entrevistado, considerando as particularidades das atividades de cada cargo e o interesse em obter uma maior quantidade de informações complementares.

Segundo Marconi e Lakatos (2007, pág. 92), "a entrevista é um encontro entre duas pessoas, a fim de que uma delas obtenha informações a respeito de determinado assunto, mediante uma conversação de natureza profissional". O diferencial da entrevista consiste no fato das informações serem passadas verbalmente, em uma conversa face a face entre o entrevistador e o entrevistado.

Ainda como fontes de pesquisas, a coleta de dados valeu-se de análise documental, importante principalmente pelo acesso a alguns relatórios e manuais de procedimentos internos, e de uma visita técnica às instalações da empresa, onde se armazenam, temporariamente, alguns dos resíduos.

Michel (2005, pág. 39), define a análise documental como uma consulta a documentos internos da instituição ou setor pesquisado, a fim de coletar dados que facilitem o entendimento do que está sendo pesquisado. A autora cita os tipos de documentos que podem se consultados: "devem ser pesquisados documentos que reflitam a natureza, a filosofia, a política da empresa, tais

\footnotetext{
${ }^{2}$ Coprocessamento é a destruição de resíduos e de passivos ambientais em fornos de cimento. A técnica, utilizada no Brasil desde o início da década de 90, consiste no uso de resíduos em substituição parcial ao combustível que alimenta a chama do forno que transforma calcário e argila em clínquer, matéria-prima do cimento.

${ }^{3}$ Incineração é o processo de destruição térmica de resíduos que ocorre em uma alta faixa de temperatura. Dentre as vantagens dessa técnica estão a destruição da maior parte dos componentes orgânicos do resíduo (percentual superior a 99,9\%) e a sua significativa redução de volume.
} 
como: regimentos, estatutos, planos de cargos e carreiras, organogramas, contratos sociais".

Fundada em 1952, pelo então governador de Minas Gerais, Juscelino Kubitschek de Oliveira, a Companhia Energética de Minas Gerais (Cemig) atua, principalmente, nas áreas de geração, transmissão e distribuição de energia elétrica. O Conglomerado Cemig é constituído por 58 empresas e 10 consórcios, sendo controlado por uma holding e suas duas subsidiárias integrais: a Cemig Geração e Transmissão S.A. e a Cemig Distribuição S.A., sediadas em Belo Horizonte/MG.

A Cemig é uma empresa de economia mista, controlada pelo Governo de Minas Gerais, que detém $51 \%$ de suas ações ordinárias. Além do controlador, a empresa possui mais de 100 mil acionistas de 44 países, com ações listadas na nas bolsas de São Paulo - BM\&F Bovespa S.A., Nova York - New York Stock Exchange (NYSE) e Madrid Mercado de Valores Latino-Americanos (Latibex).

Com cerca de 8.700 empregados diretos, a empresa possui negócios em 18 estados brasileiros e no Distrito Federal, além de estar presente no Chile, onde possui linhas de transmissão. A Companhia possui 8,7 mil $\mathrm{km}$ de linhas de transmissão e 67 usinas geradoras. $\mathrm{Na}$ área de distribuição de energia elétrica, a Cemig é responsável por aproximadamente $12 \%$ do mercado brasileiro. A Companhia possui $475 \mathrm{mil} \mathrm{km}$ de linhas de distribuição, atendendo cerca de 18 milhões de pessoas em 774 municípios.

Nos últimos cinco anos, o valor de mercado da Cemig passou de $\mathrm{R} \$ 14,3$ bilhões para $\mathrm{R} \$ 28$ bilhões. A receita operacional líquida consolidada do Conglomerado atingiu R $\$ 15,814$ bilhões em 2011, baseando-se em uma matriz cuja principal fonte de energia está nos recursos hídricos $(96,5 \%$ da capacidade instalada).

Nas três atividades principais da empresa (geração, transmissão e distribuição de energia elétrica), a Cemig atua em praticamente todo o território mineiro, sob o regime de concessão. $\mathrm{O}$ setor é regulado pela Agência Nacional de Energia Elétrica (Aneel) que é uma autarquia de regime especial (Agência Reguladora), vinculada ao Ministério de Minas e Energia. A Aneel tem o papel de regular e fiscalizar a geração, a transmissão e a distribuição/comercialização de energia elétrica no país, em conformidade com as diretrizes do Governo Federal.

\section{APRESENTAÇÃO E ANÁLISE DE DADOS}

Conforme os dados levantados por meio da análise de relatórios e das entrevistas com os gestores, constatou-se que a empresa estudada é geradora de uma grande diversidade de resíduos, sendo alguns em grande quantidade. Dentre os resíduos gerados, o relato dos entrevistados permite identificar aqueles que, pela quantidade ou pelas características, são mais evidentes no contexto organizacional. Resíduos, como óleo isolante proveniente de transformadores, lâmpadas queimadas, madeiras de embalagens, eletroeletrônicos, vidros, baterias e pneus, são tidos como os mais críticos e exigem algumas tratativas específicas.

Conforme relato do entrevistado 1, a Cemig considera, em seu processo de gerenciamento, o conceito de resíduo sólido e a classificação dados pela NBR 10.004/2004. Assim como Ribeiro e Morelli (2009), o entrevistado também defende a importância da abrangência do conceito e dos critérios que classificam os resíduos em Classe I, Classe II A e Classe II B.

Observou-se também que, além dos materiais denominados internamente como resíduos, a empresa gera uma grande quantidade de rejeitos, oriundos das atividades de manutenção, como sucatas de cabos e fios de alumínio, ferragens, componentes elétricos diversos (reatores, relés, capacitores, isoladores, medidores, etc.), postes de concreto e madeira, dentre outros. Entretanto, por não apresentarem componentes perigosos e, em contrapartida, serem valorizados no mercado de sucatas, materiais como estes são direcionados diretamente para comercialização através de leilões públicos. De acordo com Adlmaier e Sellitto (2007) a logística reversa realmente é responsável pelo retorno de materiais em diferentes condições, e não apenas resíduos. Dentre as diversas possibilidades de origem destes materiais têm-se os oriundos de obsolescência tecnológica e sobras de obras, além dos rejeitos e refugos devolvidos pelos usuários finais, entre outros.

As diferentes formas de destinação, dadas aos materiais oriundos do processo logístico reverso da empresa, estão em consonância com as argumentações de Lacerda (2009). O autor defende que produtos com características diferentes exigem tratativas específicas, incluindo o recondicionamento, a reciclagem ou o descarte final como opções de destinação destes materiais. A partir desse ponto também se evidencia a correlação entre logística reversa e gestão de resíduos, conforme proposto por Arbache et al (2007) e Araújo e Juras (2011), onde a primeira se torna importante por dispor dos mecanismos operacionais capazes de garantir desde a coleta, até a destinação final ambientalmente correta dos rejeitos industriais. 
Em termos de volume, os dados levantados nos relatórios internos de 2011 apontam para um total de 4.614 toneladas, entre resíduos e materiais inservíveis, destinados a partir do setor de logística reversa da empresa, sendo que foram alienados ou reciclados 4.381 toneladas de materiais e equipamentos, dentre os quais estão isoladores de porcelana, sucatas metálicas, sucatas de medidores, resíduo eletrônico, reatores, cabos, fios, vidro, pneus e baterias. Além disso, foram encaminhados para coprocessamento 219 toneladas de resíduos impregnados com óleo e 8,5 toneladas em equipamentos de proteção individual (EPIs). Neste mesmo período, foram alienados 693.969 litros de óleo mineral isolante impróprio para utilização em equipamentos elétricos e encaminhadas para reciclagem 435.963 lâmpadas fluorescentes queimadas, provenientes de toda a área de concessão da Cemig.

A grande variedade de resíduos gerados nos processos da empresa corroboram as citações de Ribeiro e Morelli (2009), que relacionam uma série de rejeitos gerados a partir das atividades industriais. Enquanto alguns resíduos são mais específicos ao tipo de negócio da empresa - geração, transmissão e distribuição de energia elétrica - outros, mais genéricos, são inclusive citados pelos autores, como óleos, madeira, metal, borracha (pneus) e vidros.

Em relação aos materiais apontados pelos entrevistados como resíduos, identificou-se diferentes formas de destinação. Aqueles que apresentam valor comercial, como oleosos, pneus e baterias, são vendidos a empresas especializadas em reciclagem dos respectivos materiais. Foi ressaltado pelo entrevistado 4 que as empresas adquirentes dos resíduos da Cemig passam por um processo prévio de habilitação, onde são analisadas suas licenças ambientais, e por um monitoramento sobre a destinação dos materiais retirados na empresa. Em consulta aos dados consolidados de 2011, têm-se os valores obtidos com a alienação destes materiais, são eles: R\$ 607 mil pela venda de óleo isolante, $\mathrm{R} \$ 28$ mil de baterias, $\mathrm{R} \$ 29$ mil de pneus, $\mathrm{R} \$ 2,3$ mil de vidros, $\mathrm{R} \$ 9$ mil de resíduos eletroeletrônicos e $\mathrm{R} \$ 9$ mil de madeiras. Os valores levantados com a destinação comercial dos resíduos justificam a opinião de autores como Ribeiro e Morelli (2009), que defendem a boa gestão dos rejeitos industriais como oportunidades de geração de receitas.

Outros resíduos gerados pela Cemig são destinados para reciclagem, coprocessamento ou incineração. Ao contrário da situação anterior, estes tipos de destinação são onerosos para a organização, principalmente pelos custos de transporte até as empresas recicladoras e do próprio serviço contratado. Os dados levantados junto ao entrevistado 3 indicaram um desembolso com os contratos de destinação de cerca de R $\$ 275$ mil em 2011. Entre os contratos em vigor, o colaborador destaca o de coprocessamento, contratado junto a uma cimenteira da cidade de Pedro Leopoldo, na região metropolitana de Belo Horizonte, para onde foram destinadas, no último ano, as 227,5 toneladas de materiais, a um custo total em torno de $\mathrm{R} \$ 100$ mil.

Conforme citado por Pereira et al (2012), as indústrias cimenteiras representam uma importante opção para destinação de resíduos, seja pela diversidade de materiais que podem ser destinados, seja pela grandes quantidades passíveis de serem coprocessadas no processo de fabricação de cimento. Os materiais destinados pela Cemig à cimenteira são os resíduos diversos impregnados com óleo (inclui rejeitos como terra, brita, estopa e serragem) e EPIs, que precisam ser destruídos para se evitar o risco de reutilização.

De acordo com os documentos institucionais da empresa, confirmada pelos relatos dos entrevistados, a estratégia da Cemig inclui não adotar aterro Industrial como forma de disposição dos resíduos, buscando a reciclagem ou o aproveitamento energético como forma de destinação final. O entrevistado 2 afirma que, mesmo representando uma alternativa de maior custo, a empresa opta por caminhos que minimizam os impactos ambientais. Entretanto, de acordo com o entrevistado 3, há grande dificuldade na contratação do serviço de destinação de resíduos, principalmente pelo número reduzido de empresas especializadas, sendo algumas fora do estado de Minas Gerais.

Estas constatações a respeito do tipo de destinação priorizado pela empresa se afasta da visão proposta por Pereira et al (2012) e Dias (2011), defensores da ideia de sustentabilidade como algo ainda distante da realidade empresarial. Pelo contrário, a política da empresa se aproxima do ponto de vista defendido por Ribeiro e Morelli (2009) de que a preocupação com a sustentabilidade já é algo presente no contexto organizacional global.

Outro ponto importante relacionado à destinação de resíduos é a existência de uma unidade interna de regeneração de óleo isolante. Para este fim a empresa destinou 163 mil litros de resíduos em 2011, o que, segundo o entrevistado 2 , além de representar uma redução do volume a ser destinado externamente, significa economia de recursos, pois evita a compra do material usado 
na manutenção de equipamentos. Ações como esta podem ser associadas ao conceito de ecoeficiência proposto por Almeida (2002), onde para "produzir mais com menos" torna-se necessário o investimento, por parte das organizações, em tecnologias voltadas para a redução dos volumes de rejeitos gerados ou, como no caso, tecnologias que regeneram ou transformam o resíduo em matéria prima do próprio processo produtivo.

Em relação à existência de parcerias relativas à destinação de resíduos, os entrevistados afirmaram que uma iniciativa neste sentido é a doação para cooperativas de catadores de resíduos recicláveis, principalmente plásticos e papéis, oriundos de coleta seletiva. Desta forma, identifica-se nas práticas organizacionais uma busca pela integração com agentes da sociedade conforme proposto por Barbieri (2004) e, ao mesmo tempo, põe-se em prática a responsabilidade social, segundo pilar da sustentabilidade proposto por Almeida (2002).

Entre os benefícios gerados com o gerenciamento de resíduos, os entrevistados citam, além das questões relacionadas às operações da empresa, os ganhos financeiros e de imagem. Em primeiro lugar, foram apontados ganhos diretos obtidos pela redução dos volumes armazenados em depósitos intermediários, o que torna os processos mais eficientes e, ao mesmo tempo, minimizam os riscos envolvidos no contato com resíduos perigosos. Os benefícios financeiros indicados pelos entrevistados estão relacionados com a redução dos custos de destinação, pelas receitas provenientes das vendas daqueles com valor comercial e com a minimização do risco de multas pelos órgãos fiscalizadores. Outro ponto, apontado de forma unânime pelos entrevistados, faz referência ao ganho de imagem associado à gestão de resíduos. Neste caso, destacou-se a presença da empresa por doze anos consecutivos no Índice Dow Jones de Sustentabilidade.

A listagem dos benefícios apontados pelos entrevistados está alinhada às opiniões de autores como Pereira et al (2012), Dias (2011) e Almeida (2002). A atuação punitiva dos órgãos públicos, descrita por Pereira et al (2012), justifica a preocupação financeira com as possíveis punições pela responsabilização por danos ambientais. Já os conceitos de Dias (2011) defendem, da mesma forma que os entrevistados, a ideia de valorização da imagem a partir da boa gestão de resíduos, tendo a responsabilidade ambiental como fator de competitividade empresarial. Por último, a presença da Cemig no Índice Dow Jones de Sustentabilidade indica, considerando a opinião de Almeida (2002), uma empresa vista como capaz de gerar ganhos de longo prazo, cuja administração considera os aspectos econômicos, sociais e ambientais em suas ações.

As legislações citadas pelos entrevistados, e também observadas nos registros de procedimentos internos, indicam a consideração de diversas leis e normas regulamentadoras relacionadas ao processo investigado. Além da Lei ${ }^{\circ}$ 12.305/2010 (Lei dos Resíduos Sólidos), foram destacadas as implicações referentes às Leis 6.938/81 (Política Nacional do Meio Ambiente) e 9.605/98 (Lei de Crimes Ambientais). Também são citadas a NBR 10.004/04 (Resíduos Sólidos - Classificação) e a Resolução 420/04 da Agência Nacional de Transportes Terrestres (ANTT) que regulamenta o transporte terrestre de produtos perigosos. Este conjunto de leis consideradas internamente vai ao encontro dos relatos de Araújo e Juras (2011), uma vez que as autoras também citam diversas leis - algumas coincidentes - relacionadas o processo de destinação de resíduos.

Os relatos dos entrevistados se mostram divergentes a respeito do nível de integração entre as áreas da empresa nas questões relacionadas aos resíduos. Se por um lado os entrevistados 2 e 3 afirmam que há um esforço conjunto para cumprir a política ambiental da empresa e se adequar às normas e legislações ambientais, por outro, os entrevistados 1 e 4 tecem observações negativas. Ambos consideram o tamanho da empresa como dificultador, sendo que o entrevistado 1 levanta problemas operacionais relacionados ao controle da geração e aos processo de segregação e de transporte dos resíduos da empresa. Já o entrevistado 4 considera necessário investir em conscientização de todo o grupo Cemig e buscar um maior envolvimento com a área de compras da empresa, de forma a envolver os fornecedores nos processos de logística reversa e, consequentemente, nas responsabilidades pela destinação final dos materiais.

Partindo-se de uma análise mais abrangente, estas informações permitem identificar que, apesar de não ser aplicado no processo de logística reversa da empresa, há uma valorização da visão sistêmica sobre o ciclo de vida dos produtos, conforme defendido por Gonçalves e Marins (2006), onde se atribui aos fabricantes a responsabilidade pela destinação final dos materiais. Dessa forma, nota-se o anseio pela aplicação, também no sentido reverso, do conceito de Gerenciamento da Cadeia de Suprimentos (GCS) conforme apresentado por Ballou (2006), o que significa a aplicação da logística de forma integrada, levando-se em consideração todos envolvidos no canal de fluxo 
dos produtos, no âmbito da empresa e também fora dela.

\section{CONSIDERAÇÕES FINAIS}

Tendo sido o objetivo deste artigo investigar, a partir do ponto de vista interno, a relevância da gestão de resíduos para a organização, constatou-se que se trata de uma questão complexa e ainda não consolidada, mas com demandas importantes no âmbito de atuação da empresa. Inserido dentro do processo de logística reversa, o gerenciamento de resíduos inclui atividades que visam zelar pela imagem da empresa em questões relacionadas à preservação do meio ambiente, buscando, ao mesmo tempo, alternativas menos dispendiosas, ou até mesmo rentáveis para a organização.

A complexidade identificada no processo de gestão de resíduos pode ser considerada a partir de diversos ângulos, dentre os quais estão as questões relacionadas à legislação e a diversidade de resíduos a serem destinados, exigindo tratativas diferenciadas. Verificou-se, tanto no levantamento teórico como na pesquisa de campo, uma série de leis e regulamentações que exigem uma compreensão detalhada, a fim de, por exemplo, evitar o risco de uma autuação por descumprimento de um requisito legal. O estudo de campo também revelou que as atividades da empresa geram uma grande diversidade de resíduos, cuja destinação é específica em cada caso e demanda sistemas diferenciados de gestão, visando maior controle, principalmente pelo envolvimento de terceiros.

Releva-se ainda a amplitude de alcance das ações ligadas a esse processo, onde uma falha pode gerar desde riscos físicos, como, por exemplo, em situações de armazenamento inadequado, a até perdas financeiras substanciais, no caso de um incidente que comprometa a imagem da empresa, rebaixando seu valor de mercado. Diante disso, o estudo de caso permitiu observar que existe na empresa uma conscientização interna sobre os benefícios advindos da boa gestão de resíduos, estejam eles relacionados aos ganhos em eficiência operacional, aos retornos financeiros ou à valorização da imagem institucional. Destaca-se, por exemplo, que, uma vez ciente da necessidade de monitoramento das questões relacionadas aos resíduos, para continuar compondo o Índice Dow Jones de Sustentabilidade, as ações corporativas demonstram esforço para garantir o atendimento às normas e regulamentações, além do desenvolvimento de iniciativas pioneiras nesse sentido.

Em relação às alternativas econômicas obtidas a partir do gerenciamento de resíduos, constatou-se a geração de receitas expressivas com a comercialização de alguns materiais que, a princípio, seriam fontes de despesas. Destaca-se a preocupação da organização com o acompanhamento pós-venda, de forma a garantir uma destinação adequada pelas empresas adquirentes. Os funcionários da empresa se mostram cientes de que a possibilidade de encaminhar resíduos para reciclagem, além de representar uma fonte de receitas, também significa uma aplicação mais benéfica para a natureza, pois elimina um volume de material que seria dispensado em aterros e, ao mesmo tempo, substitui matérias-primas virgens, cuja obtenção é mais prejudicial ao meio ambiente.

Outros pontos observados no estudo de caso, avaliados como positivos, são a manutenção de uma unidade interna de regeneração de óleos usados e a existência de parceria com uma associação de catadores, para onde são doados os resíduos provenientes da coleta seletiva. O primeiro caso, tratamento interno de parte dos resíduos gerados, transformando-os em componente reutilizável nos processos de manutenção de equipamentos, se traduz principalmente na melhoria da eficiência organizacional, com a redução dos recursos consumidos em tais atividades. Já a doação de material para fins de reciclagem, beneficiando uma associação de catadores, mesmo sendo uma ação essencialmente local, pode influenciar positivamente a imagem da empresa, uma vez que está relacionada simultaneamente com os conceitos de responsabilidade ambiental e social.

Constatou-se, através da pesquisa, que aspectos externos, como o número restrito de empresas especializadas em destinar resíduos, impactam negativamente o processo de gestão interno. Além da dificuldade em encontrar fornecedores qualificados, a baixa concorrência nas licitações tende a tornar os preços mais altos. Outra questão externa com interferência direta sobre o processo da empresa é a própria legislação, cujo principal instrumento regulamentador, a Lei dos Resíduos Sólidos (Lei no 12.305 de 02/08/2010), está em vigor há menos de dois anos. Apesar de apontada internamente como um ponto positivo, uma vez que a nova lei passou a ser vista como um elemento norteador das ações da empresa, sugere-se que a partir de uma nova legislação os procedimentos internos devam passar por revisões para se adequarem integralmente aos novos preceitos legais.

Os levantamentos a respeito do nível de integração, entre as diversas áreas internas, em torno das atividades voltadas para o gerenciamento 
de resíduos, indicam haver um esforço conjunto no sentido de cumprir a política ambiental da empresa. Entretanto, o tamanho e a complexidade da estrutura organizacional dificultam o alcance de resultados mais abrangentes. Inclui-se, novamente, o desafio identificado a partir da grande diversidade de resíduos gerados e da necessidade de tratamentos específicos para cada tipo. Dessa forma, o sucesso na adequação da destinação para um determinado material pode ser ofuscado pelas falhas e, consequentemente, pelo passivo gerado a partir de outro resíduo completamente diferente.

Considerando que as informações levantadas permitiram identificar algumas interfaces do Setor de Gestão de Resíduos, constatou-se que a logística reversa se mostra como a porta de entrada para as atividades relacionadas à gestão dos rejeitos industriais. Uma vez envolvido o produto "resíduo", as atividades geralmente associadas ao processo logístico, como segregação de materiais, embalagem, movimentação, transporte e armazenamento temporário, referem-se a um fluxo reverso de materiais, onde novas implicações devem ser consideradas. Neste ponto ocorrem as interações entre logística reversa e gestão de resíduos, evidenciando a necessidade de proximidade entre as áreas. No caso da Cemig, essa proximidade é definida na estrutura hierárquica, uma vez que o Setor de Gestão de Resíduos é posicionado como um sub-processo da Logística Reversa.

Diante das possibilidades de destinação dadas aos resíduos oriundos das atividades da Cemig, o que não inclui a devolução ao fabricante/ fornecedor, constata-se que a atuação do Setor de Logística Reversa está voltada para as operações no interior da empresa. Ou seja, pelas características, ou pela abrangência espacial das atividades da empresa, ou mesmo por opção gerencial, o processo denominado na organização como logística reversa ocupa-se primordialmente com o trânsito interno de materiais pós-consumo. A Gestão de Resíduos, tida então como a última etapa do processo reverso de circulação de material, promove a destinação correta envolvendo um terceiro agente - sejam clientes, quando adquirem componentes com valor comercial, sejam fornecedores, quando prestam os serviços de tratamento dos resíduos da empresa.

De forma geral, a elaboração deste artigo possibilitou identificar uma série de vantagens atreladas ao gerenciamento de resíduos, com destaque para a minimização do risco de intervenções de órgãos fiscalizadores, as possibilidades de ganhos financeiros e a consequente valorização da imagem institucional. Apesar de se tratar de um estudo pontual, onde a amostra se resume ao contexto de uma única empresa, os levantamentos indicaram uma relativa consonância entre a teoria e a prática, principalmente em termos da importância e dos benefícios da gestão de resíduos, com resultado positivo para a organização. Dessa forma, sugere-se que o gerenciamento de resíduos de forma responsável seja um caminho viável, principalmente em termos de sustentabilidade.

Vale ressaltar que o estudo realizado se restringiu aos aspectos internos da gestão de resíduos, com foco para o negócio de uma empresa específica. Dessa forma, o artigo está longe de englobar todas as considerações inerentes ao assunto, principalmente considerando as características exclusivas a outros setores. Diante disso, identifica-se a possibilidade de novos estudos relacionados à gestão de resíduos que permitam explorar, dentre outros fatores, novas alternativas para a destinação final dos mais variados materiais.

\section{REFERÊNCIAS}

ADLMAIER, Diogo; SELLITTO, Miguel Afonso. Embalagens retornáveis para transporte de bens manufaturados: um estudo de caso em logística reversa. Universidade do Vale do Rio dos Sinos. São Leopoldo: PRODUÇÃO, v. 17, n. 2, p. 395 406, Mai./Ago. 2007. Disponível em: <http://www. scielo.br/pdf/prod/v17n2/ a14v17n2.pdf>. Acesso em: 29 abr. 2012.

ALMEIDA, Fernando. O bom negócio da sustentabilidade. Rio de Janeiro: Nova Fronteira: 2002. 191 p.

ARAÚJO, Suely Mara Vaz Guimarães de; JURAS, Ilidia da Ascenção Garrido Martins. Comentários à Lei dos resíduos sólidos: Lei n ${ }^{\circ} 12.305$, de 2 de agosto de 2010 (e seu regulamento). São Paulo: Pillares, 2011. 255 p.

ARBACHE, Fernando Saba et al. Gestão de logística, distribuição e trade marketing. 3. ed. Rio de Janeiro: FGV, 2007. 164 p.

ASSOCIAÇÃO BRASILEIRA DE NORMAS TÉCNICAS - ABNT. NBR 10.004. Resíduos Sólidos Classificação. 2. ed. Rio de Janeiro, 2004. 71 p.

BALLOU, Ronald H.. Gerenciamento da cadeia de suprimentos/logística empresarial. Tradução de Raul Rubenich. 5. ed. Porto Alegre: Bookman, 2006. $616 \mathrm{p}$. 
BARBIERI, José Carlos. Gestão ambiental empresarial: conceitos, modelos e instrumentos. São

Paulo: Saraiva, 2004. 328p.

BRASIL. Lei n. 12.305, de 2 de agosto de 2010. Institui a Política Nacional de Resíduos Sólidos; altera a Lei no 9.605, de 12 de fevereiro de 1998; e dá outras providências. Ministério do Meio Ambiente - MMA. Disponível em: <http://www.mma.gov.br/ port/conama/legiabre.cfm?codlegi $=636>$. Acesso em: 29 abr. 2012.

CERVO, Amado Luiz; BERVIAN, Pedro Alcino. Metodologia Científica. 5. ed. São Paulo: Prentice Hall, 2002. 242 p.

DIAS, Reinaldo. Gestão Ambiental: responsabilidade e sustentabilidade. 2. ed. São Paulo: Atlas, 2011. 220p.

GONÇALVES, Marcus Eduardo; MARINS, Fernando Augusto Silva. Logística reversa numa empresa de laminação de vidros: um estudo de caso. GESTÃO \& PRODUÇÃO, Guaratinguetá, v.13, n.3, p.397-410, set./dez. 2006. Disponível em: <http:// www.scielo.br/pdf/gp/v13n3/03.pdf > . Acesso em: 2 abr. 2012.

LACERDA, Leonardo. Logística Reversa: Uma visão sobre os conceitos básicos e as práticas operacionais. Brasil: Logística Total, 2009. Disponível em: <http://logisticatotal.com.br/files/articles/ d92655a96a539bf0855101ef302acd17.pdf > Acesso em: 2 abr. 2012.

LEITE, Paulo Roberto. Logística Reversa: Meio Ambiente e Competitividade. São Paulo: Prentice Hall, 2003. 250p.

MARCONI, Marina de Andrade; LAKATOS, Eva Maria. Técnicas de Pesquisa: planejamento e execução de pesquisas, amostragens e técnicas de pesquisas, elaboração, análise e interpretação de dados. 6 . ed. 2. reimpr. São Paulo: Atlas, 2007. 289 p.

MICHEL, Maria Helena. Metodologia e Pesquisa Científica em Ciências Sociais. São Paulo: Atlas, $2005.138 \mathrm{p}$.

PEREIRA, André Luiz et al. Logística Reversa e Sustentabilidade. São Paulo: Cengage Learning, 2012. 192p.

POZO, Hamilton. Administração de recursos mate- riais e patrimoniais: uma abordagem logística. 3. ed. São Paulo: Atlas, 2004. 204 p.

RIBEIRO, Daniel Véras; MORELLI, Márcio Raymundo. Resíduos sólidos: problema ou oportunidade? Rio de Janeiro: Interciência, 2009.135 p.

SOUZA, Sueli Ferreira de; FONSECA, Sérgio Ulisses Lage da. Logística Reversa: oportunidades para redução de custos em decorrência da evolução do fator ecológico. Guarulhos: Revista Terceiro Setor, v.3, n.1, 2009. Pag. 29 - 39. Disponível em: $<$ http://revistas.ung.br/index.php/3setor/article/ viewFile/512/606> Acesso em: 01 abr. 2012. 